\title{
Estimasi Pertumbuhan Penduduk Di Kabupaten Tasikmalaya Menggunakan Metode Regresi Linear Berganda
}

\author{
Estimation of Population Growth in Tasikmalaya District Using Multiple Linear Regression \\ Methods
}

\author{
Evi Dewi Sri Mulyani' ${ }^{1}$, Algi Muhamad Sahrin², Dea Rizki Pratama ${ }^{3}$, Dinda Regina \\ Puspitasari $^{4}$, Eka Suparman Pamungkas ${ }^{5}$, Luthfi Fauzi Rahman ${ }^{6}$, Mufti Ali ${ }^{7}$ \\ Program Studi Teknik Informatika, STMIK Tasikmalaya \\ E-mail: 1evidewisrimulyani@gmail.com, 22algi.moch.syahrin@gmail.com, \\ 33dearizkipratamapcs@gmail.com, ${ }^{4}$ dindareginapuspitasari2@gmail.com, ${ }^{5}$ ekaamd21@gmail.com, \\ ${ }^{6}$ luthfifauzirahman@gmail.com, ${ }^{7}$ muftiali@gmail.com
}

\begin{abstract}
Abstrak
Estimasi merupakan salah satu cara unutk menentukan jumlah data dalam waktu terntentu. Dalam sehari - hari estimasi digunakan untuk menghitung perkiraan waktu ataupun memperkiraan pertumbuhan data. Pertumbuhan penduduk yang semakin meningkat dari tahun ketahun secara tidak langsung mengakibatkan jumlah lowongan kerja semakin sedikit, Oleh karena itu kami memilih estimasi untuk menghitung laju pertumbuhan penduduk beserta pengangguran di kabupaten tasikmalaya untuk membantu pemerintah dalam menyiapkan program mendatang seperti membuat pelatihan sumber daya manusia agar penduduk dikabupaten tasikmalaya menjadi penduduk yang mandiri. Dalam penelitian ini Kami menggunakan metode Regresi Linear Berganda. Hasil yang di peroleh adalah banyakanya jumlah pengangguran pada tahun 2018 yang mencapai 62352 orang, Maka dari itu estimasi menggunakan metode regresi linear berganda dapat dijadikan referensi dalam melakukan perhitungan jumlah pengangguran di Tasikmalaya.
\end{abstract}

Kata Kunci-3-5 Data mining, estimasi, regresi linear

\begin{abstract}
Estimation is one way to determine the amount of data in a certain time. In day-to-day estimation is used to calculate estimated time or estimate data growth. Population growth is increasing from year to year indirectly resulting in fewer job vacancies. Therefore, we choose estimates to calculate the rate of population growth and unemployment in Tasikmalaya Regency to assist the government in preparing future programs such as training human resources so that residents in the regency Tasikmalaya becomes an independent resident. In this study we use the Multiple Linear Regression method. The results obtained are mostly the number of unemployed in 2018 which reached 62352 people, so from that estimation using multiple linear regression methods can be used as a reference in calculating the number of unemployed in Tasikmalaya.
\end{abstract}

Keywords - 3-5 Data mining, estimation, linear regression

\section{PENDAHULUAN}

Pertumbuhan Penduduk ialah suatu perubahan populasi sewaktu-waktu, dan bisa dihitung sebagai perubahan dalam jumlah individu dalam sebuah populasi. Kelahiran yang menjadi faktor pertumbuhan penduduk dan dipengaruhi dari menikah di usia muda dan tidak melaksanan program keluarga berencana yang mengakibatkan meningkatnya angka kelaharian. Pada pembaharuan terbaru Badan Pusat Statistik Kabupaten Tasikmalaya mencatat pada tahun 2016 terdapat 1.742.276 jiwa dan pada tahun 2017 terdapat 1.747.318 jiwa[1]. 
Pertumbuhan penduduk yang semakin meningkat dari tahun ketahun secara tidak langsung mengakibatkan jumlah lowongan kerja semakin sedikit. Dengan adanya penerapan data mining untuk menentukan estimasi pertumbuhan penduduk diharapkan dapat membantu pemerintah dalam menyiapkan program mendatang seperti membuat pelatihan sumber daya manusia agar penduduk dikabupaten tasikmalaya menjadi penduduk yang mandiri maka dari itu tingkat pendapatan penduduk akan menjadi lebih baik dan tingkat pengangguran akan berkurang. Maka dari itu kami mengambil kesempatan untuk melakukan sebuah penelitian dengan penerapan data mining untuk menentukan estimasi pertumbuhan penduduk tahun 2018 di Kabupaten Tasikmalaya menggunakan metode regresi linear berganda[2].

Algoritma Regresi Linear termasuk jenis aturan classification and regression pada data mining, selain Regresi Linear yang termasuk pada golongan ini adalah Support Vector Machine, Logistic Regression dan lain-lain. Alasan utama menggunakan data mining dengan metode regresi linier berganda adalah untuk membantu dalam analisis koleksi pengamatan perilaku. Estimasi untuk menerka sebuah nilai yang belum diketahui Regresi linear merupakan satu cara yang menggunakan garis lurus unutk menggambarkan hubungan diantara dua variabel atau lebih. Variabel adalah besaran yang berubah-ubah nilainya. Selanjutnya variabel tersebut terbagi atas dua jenis yaitu variabel pemberi pengaruh dan variabel terpengaruh. Variabel pemberi pangaruh dapat dianalogikan sebab, sementara variabel terpengaruh merupakan akibat[3]. 


\section{METODE PENELITIAN}

Adapun tahapan-tahapan yang dilakukan dalam penelitian. Diawali dengan pengajuan masalah lalu penyusunan kerangka teoritis dan hipotesis langsung pada metodologi penelitian lalu hasil penelitian dan terakhir membuat ringkasan dan kesimpulan akhir sebagai hasil dari hipotesis sebelumnya.

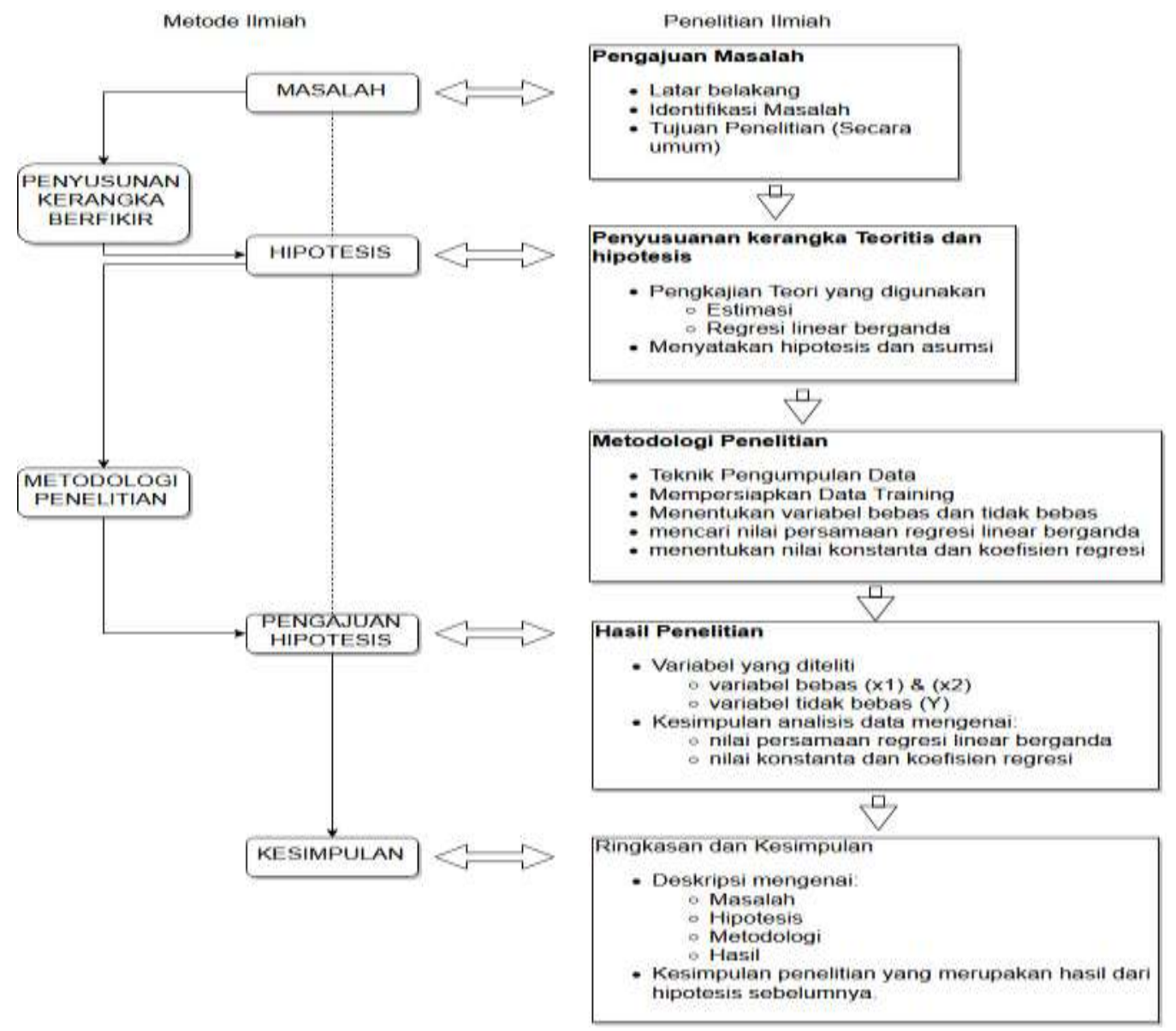

Gambar 1 Kerangka Penelitian

Pada gambar diatas dalam penyelesaian permasalahan akan dikaji dengan menggunakan regresi linier berganda. Dalam kasus ini akan diambil dari database yang ada pada BPS Kabupaten Tasikmalaya tahun 2010 sampai tahun 2017 sebanyak 2 database dengan 117 dataset. Data tersebut akan digunakan dalam perhitungan metode regresi linear berganda untuk menganalisa mengenai mengestimasi pengangguran. Data pengangguran tersebut selanjutnya akan dilakukan pra-proses untuk menghasilkan data khusus yang siap untuk dibentuk menjadi sebuah informasi baru.

\section{HASIL DAN PEMBAHASAN}

Ada beberapa tahapan dalam membuat penyelesaian masalah dengan metode regresi linear berganda. Pertama mempersiapkan data training. Data training biasanya diambil dari data histori yang pernah terjadi sebelumnya atau disebut data masa lalu dan sudah dikelompokkan dalam kelaskelas tertentu. Kemudian menentukan variabel bebas dan variabel tidak bebas : 
- Variabel bebas yaitu :

Jumlah Laki-Laki (X1)

Jumlah Perempuan (X2)

- Variabel tidak bebas yaitu :

Jumlah Penduduk (Y)

Setelah itu mencari nilai persamaan regresi linear berganda dengan rumus :

$\mathrm{Y}=\mathrm{a}+\mathrm{b} 1 \cdot \mathrm{x} 1+\mathrm{b} 2 \cdot \mathrm{x} 2$

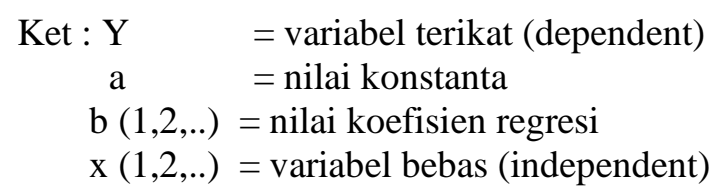

terakhir menentukan nilai konstanta dan koefisien regresi.

Berikut langkah pengerjaan menentukan estimasi laju pertumbuhan penduduk di kabupaten Tasikmalaya dengan menggunakan metode regresi linear berganda:

1. Mempersiapkan data training

Tabel.1 Database Penduduk Kabupaten Tasikmalaya

Jumlah Penduduk dan Laju Pertumbuhan

Penduduk Menurut Kecamatan di Kabupaten

Tasikmalaya, 2010, 2016, dan 2017

\begin{tabular}{|c|l|c|c|c|}
\hline \hline \multirow{2}{*}{\begin{tabular}{l}
\multirow{2}{*}{$\begin{array}{l}\text { Kecamatan } \\
\text { Subdistrict }\end{array}$} \\
\cline { 3 - 5 }
\end{tabular}} & \multicolumn{3}{|c|}{$\begin{array}{c}\text { Jumlah Penduduk (jiwa) } \\
\text { Population (person) }\end{array}$} \\
\cline { 2 - 5 } & $\mathbf{2 0 1 0}$ & $\mathbf{2 0 1 6}$ & $\mathbf{2 0 1 7}$ \\
\hline 1 & Cipatujah & 63.312 & 65.354 & $(4)$ \\
\hline 2 & Karangnunggal & 81.521 & 84.156 & 65.541 \\
\hline 3 & Cikalong & 61.624 & 63.615 & 64.399 \\
\hline 4 & Pancatengah & 44.941 & 46.391 & 46.527 \\
\hline 5 & Cikatomas & 48.075 & 49.626 & 49.771 \\
\hline 6 & Cibalong & 30.702 & 31.694 & 31.785 \\
\hline 7 & Parungponteng & 33.714 & 34.804 & 34.904 \\
\hline 8 & Bantarkalong & 34.491 & 35.604 & 35.706 \\
\hline 9 & Bojongasih & 19.318 & 19.942 & 20.000 \\
\hline 10 & Culamega & 23.079 & 23.825 & 23.895 \\
\hline 11 & Bojonggambir & 38.619 & 39.866 & 39.983 \\
\hline 12 & Sodonghilir & 63.034 & 65.072 & 65.261 \\
\hline 13 & Taraju & 37.628 & 38.844 & 38.958 \\
\hline 14 & Salawu & 57.938 & 59.808 & 59.981 \\
\hline 15 & Puspahiang & 32.912 & 33.975 & 34.068 \\
\hline 16 & Tanjungjaya & 42.643 & 44.020 & 44.149 \\
\hline 17 & Sukaraja & 49.142 & 50.727 & 50.874 \\
\hline 18 & Salopa & 48.684 & 50.254 & 50.398 \\
\hline 19 & Jatiwaras & 48.173 & 49.729 & 49.872 \\
\hline & & & & \\
\hline
\end{tabular}




\begin{tabular}{|r|l|c|c|c|}
\hline 20 & Cineam & 33.531 & 34.614 & 34.716 \\
\hline 21 & Karangjaya & 12.464 & 12.866 & 12.902 \\
\hline 22 & Manonjaya & 60.687 & 62.644 & 62.824 \\
\hline 23 & Gunungtanjung & 27.765 & 28.662 & 28.744 \\
\hline 24 & Singaparna & 66.054 & 68.187 & 68.385 \\
\hline 25 & Mangunreja & 39.238 & 40.505 & 40.624 \\
\hline 26 & Sukarame & 37.023 & 38.218 & 38.330 \\
\hline 27 & Cigalontang & 68.154 & 70.354 & 70.558 \\
\hline 28 & Leuwisari & 36.754 & 37.941 & 38.052 \\
\hline 29 & Padakembang & 30.529 & 31.518 & 31.608 \\
\hline 30 & Sariwangi & 35.837 & 36.997 & 37.103 \\
\hline 31 & Sukaratu & 44.192 & 45.619 & 45.752 \\
\hline 32 & Cisayong & 53.110 & 54.825 & 54.983 \\
\hline 33 & Sukahening & 29.585 & 30.540 & 30.628 \\
\hline 34 & Rajapolah & 44.800 & 46.245 & 46.379 \\
\hline 35 & Jamanis & 32.485 & 33.533 & 33.631 \\
\hline 36 & Ciawi & 58.009 & 59.882 & 60.054 \\
\hline 37 & Kadipaten & 32.995 & 34.059 & 34.157 \\
\hline 38 & Pagerageung & 51.592 & 53.257 & 53.413 \\
\hline 39 & Sukaresik & 33.422 & 34.504 & 34.604 \\
\hline \multicolumn{2}{|l|}{ Tasikmalaya } & 1.687 .776 & 1.742 .276 & 1.747 .318 \\
\hline \hline
\end{tabular}

Data diatas merupakan Data training yang biasanya diambil dari data histori yang pernah terjadi sebelumnya atau disebut data masa lalu dan sudah dikelompokkan dalam kelas-kelas tertentu. Di tabel 1 dapat dilihat disana kami mengambil data laju pertumbuhan penduduk per kecamatan di kabupaten tasikmalaya pada tahun 2010, 2016, dan 2017.

2. Setelah menyiapkan data training selanjutnya menentukan variabel bebas dan variabel tidak bebas, yaitu menentukan jumlah laki-laki dan perempuannya.

Tabel.2 Akumulasi Data Penduduk Per Tahun Berdasarkan Jenis Kelamin

\begin{tabular}{|c|c|c|c|}
\hline \multirow{2}{*}{$\begin{array}{c}\text { Kelompok } \\
\text { Umur } \\
\text { Age Group }\end{array}$} & $\begin{array}{c}|c| \\
\text { Jenis Kelamin/Sex } \\
\text { Male }\end{array}$ & $\begin{array}{c}\text { Perempuan } \\
\text { Female }\end{array}$ & $\begin{array}{c}\text { Jumlah } \\
\text { Total }\end{array}$ \\
\hline$(1)$ & $(2)$ & $(3)$ & $(4)$ \\
\hline $0-4$ & 74980 & 72380 & 147360 \\
\hline $5-9$ & 80260 & 76838 & 157098 \\
\hline $10-14$ & 81880 & 77700 & 159580 \\
\hline $15-19$ & 70240 & 68171 & 138411 \\
\hline $20-24$ & 54147 & 58925 & 113072 \\
\hline $25-29$ & 54272 & 59275 & 113547 \\
\hline $30-34$ & 54386 & 58330 & 112716 \\
\hline $35-39$ & 62462 & 68844 & 131306 \\
\hline $40-44$ & 66084 & 67591 & 133675 \\
\hline $45-49$ & 66000 & 64101 & 130101 \\
\hline
\end{tabular}




\begin{tabular}{|c|r|r|r|}
\hline $50-54$ & 53293 & 53488 & 106781 \\
\hline $55-59$ & 43110 & 44771 & 87881 \\
\hline $60-64$ & 38611 & 38081 & 76692 \\
\hline $65-69$ & 27266 & 27447 & 54713 \\
\hline $70-74$ & 18523 & 20063 & 38586 \\
\hline $75+$ & 19957 & 25842 & 45799 \\
\hline Jumlah/Total & $\mathbf{8 6 5 4 7 1}$ & $\mathbf{8 8 1 ~ 8 4 7}$ & $\mathbf{1 7 4 7 3 1 8}$ \\
\hline
\end{tabular}

Tabel.3 Penyederhanaan Data Penduduk (dibagi 1000)

\begin{tabular}{|l|c|c|c|}
\hline \multirow{2}{*}{ Umur } & \multicolumn{2}{|c|}{ Jenis Kelamin } & \multirow{2}{*}{ Jumlah } \\
\cline { 2 - 3 } & $\begin{array}{c}\text { Laki - } \\
\text { laki }\end{array}$ & Perempuan & \\
\hline $0-4$ & 74,98 & 72,38 & 147,36 \\
\hline $5-9$ & 80,26 & 76,838 & 157,098 \\
\hline $10-14$ & 81,88 & 77,7 & 159,58 \\
\hline $15-19$ & 70,24 & 68,171 & 138,411 \\
\hline $20-24$ & 54,147 & 58,925 & 113,072 \\
\hline $25-29$ & 54,272 & 59,275 & 113,547 \\
\hline $30-34$ & 54,386 & 58,33 & 112,716 \\
\hline $35-39$ & 62,462 & 68,844 & 131,306 \\
\hline $40-44$ & 66,084 & 67,591 & 133,675 \\
\hline $45-49$ & 66 & 64,101 & 130,101 \\
\hline $50-54$ & 53,293 & 53,488 & 106,781 \\
\hline $55-59$ & 43,11 & 44,771 & 87,881 \\
\hline $60-64$ & 38,611 & 38,081 & 76,692 \\
\hline $65-69$ & 27,266 & 27,447 & 54,713 \\
\hline $70-74$ & 18,523 & 20,063 & 38,586 \\
\hline $75+$ & 19,957 & 25,842 & 45,799 \\
\hline Jumlah & 865,471 & 881,847 & 1747,318 \\
\hline & $X 1$ & $X 2$ & $Y$ \\
\hline
\end{tabular}

Dari tabel diatas dapat dilihat bahwasanya jumlah laki-laki dan perempuan dari umur 0-75+ sebanyak 1747,318 orang.

3. Setelah menentukan variabel bebas dan variabel tak bebas selanjutnya mencari nilai persamaan regresi linear.

Tabel.4 Ikhtisar Perhitungan

\begin{tabular}{|c|c|c|c|c|c|}
\hline Umur & $X 1^{\wedge} 2$ & $\mathrm{X} 1 * \mathrm{X} 2$ & $\mathbf{X} 1 * \mathbf{Y}$ & $X 2^{\wedge} 2$ & $\mathbf{X} 2 * \mathbf{Y}$ \\
\hline $0-4$ & 5622,0 & 5427,1 & 11049,1 & 5238,9 & 10665,9 \\
\hline $5-9$ & 6441,7 & 6167,0 & 12608,7 & 5904,1 & 12071,1 \\
\hline $10-14$ & 6704,3 & 6362,1 & 13066,4 & 6037,3 & 12399,4 \\
\hline
\end{tabular}




\begin{tabular}{|r|r|r|r|r|r|}
\hline $15-19$ & 4933,7 & 4788,3 & 9722,0 & 4647,3 & 9435,6 \\
\hline $20-24$ & 2931,9 & 3190,6 & 6122,5 & 3472,2 & 6662,8 \\
\hline $25-29$ & 2945,4 & 3217,0 & 6162,4 & 3513,5 & 6730,5 \\
\hline $30-34$ & 2957,8 & 3172,3 & 6130,2 & 3402,4 & 6574,7 \\
\hline $35-39$ & 3901,5 & 4300,1 & 8201,6 & 4739,5 & 9039,6 \\
\hline $40-44$ & 4367,1 & 4466,7 & 8833,8 & 4568,5 & 9035,2 \\
\hline $45-49$ & 4356,0 & 4230,7 & 8586,7 & 4108,9 & 8339,6 \\
\hline $50-54$ & 2840,1 & 2850,5 & 5690,7 & 2861,0 & 5711,5 \\
\hline $55-59$ & 1858,5 & 1930,1 & 3788,5 & 2004,4 & 3934,5 \\
\hline $60-64$ & 1490,8 & 1470,3 & 2961,2 & 1450,2 & 2920,5 \\
\hline $65-69$ & 743,4 & 748,4 & 1491,8 & 753,3 & 1501,7 \\
\hline $70-74$ & 343,1 & 371,6 & 714,7 & 402,5 & 774,2 \\
\hline $75+$ & 398,3 & 515,7 & 914,0 & 667,8 & 1183,5 \\
\hline Jumlah & 52835,7 & 53208,6 & 106044,3 & 53771,8 & 106980,4 \\
\hline
\end{tabular}

Tabel diatas merupakan ikhtisar perhitungan dimana untuk mempermudah melihat jumlah dari nilai perkalian $\mathrm{X}$ dan $\mathrm{Y}$.

Tabel.5 Penyederhanaan Ikhtisar Perhitungan (dibagi 100)

\begin{tabular}{|c|r|r|r|r|r|}
\hline Umur & \multicolumn{1}{|c|}{$\mathrm{X} 1^{\wedge} 2$} & $\mathrm{X} 1 * \mathrm{X} 2$ & \multicolumn{1}{|c|}{$\mathrm{X} 1^{*} \mathrm{Y}$} & \multicolumn{1}{|c|}{$\mathrm{X} 2^{\wedge} 2$} & \multicolumn{1}{|c|}{$\mathrm{X} 2^{*} \mathrm{Y}$} \\
\hline $0-4$ & 56,2200 & 54,2705 & 110,4905 & 52,3886 & 106,6592 \\
\hline $5-9$ & 64,4167 & 61,6702 & 126,0869 & 59,0408 & 120,7110 \\
\hline $10-14$ & 67,0433 & 63,6208 & 130,6641 & 60,3729 & 123,9937 \\
\hline $15-19$ & 49,3366 & 47,8833 & 97,2199 & 46,4729 & 94,3562 \\
\hline $20-24$ & 29,3190 & 31,9061 & 61,2251 & 34,7216 & 66,6277 \\
\hline $25-29$ & 29,4545 & 32,1697 & 61,6242 & 35,1353 & 67,3050 \\
\hline $30-34$ & 29,5784 & 31,7234 & 61,3017 & 34,0239 & 65,7472 \\
\hline $35-39$ & 39,0150 & 43,0013 & 82,0164 & 47,3950 & 90,3963 \\
\hline $40-44$ & 43,6710 & 44,6668 & 88,3378 & 45,6854 & 90,3523 \\
\hline $45-49$ & 43,5600 & 42,3067 & 85,8667 & 41,0894 & 83,3960 \\
\hline $50-54$ & 28,4014 & 28,5054 & 56,9068 & 28,6097 & 57,1150 \\
\hline $55-59$ & 18,5847 & 19,3008 & 37,8855 & 20,0444 & 39,3452 \\
\hline $60-64$ & 14,9081 & 14,7035 & 29,6115 & 14,5016 & 29,2051 \\
\hline $65-69$ & 7,4343 & 7,4837 & 14,9180 & 7,5334 & 15,0171 \\
\hline $70-74$ & 3,4310 & 3,7163 & 7,1473 & 4,0252 & 7,7415 \\
\hline $75+$ & 3,9828 & 5,1573 & 9,1401 & 6,6781 & 11,8354 \\
\hline Jumlah & 528,3568 & 532,0857 & 1060,4425 & 537,7181 & 1069,8037 \\
\hline
\end{tabular}

Tabel diatas merupakan penyederhanaan ikhtisar perhitungan dimana untuk mempermudah melihat jumlah dari nilai perkalian X dan Y dibagi 100 agar mudah dalam melakukan perhitungan regresi linear nya. 
4. Selannjutnya Untuk memperoleh koefisien regresi a, b1 dan b2 dapat diperoleh dengan cara simultan dari tiga persamaan sebagai berikut:

$a n+b 1 \Sigma \mathrm{X} 1+b 2 \Sigma \mathrm{X} 2=\Sigma \mathrm{Y}$

$a \Sigma \mathrm{X} 1+b 1 \Sigma \mathrm{X} 12+b 2 \Sigma \mathrm{X} 1 \mathrm{X} 2=\Sigma \mathrm{X} 1 \mathrm{Y}$

$a \Sigma \mathrm{X} 2+b 1 \Sigma \mathrm{X} 1 \mathrm{X} 2+b 2 \Sigma \mathrm{X} 22=\Sigma \mathrm{X} 2 \mathrm{Y}$

Mengikuti rumus persamaan di atas maka :

$16 a+865,471 b 1+881,847 b 2=1747,318$

$865,471 a+b 1528,357+532,086 b 2=1060,44$

$881847 a+532,085 b 1+537,718 b 2=1069,80$

Selanjutnya ketiga persamaan di atas akan kita eliminasi. Yang pertama kita akan mengitung rumus 1 dan 2.

Persamaan 1

\begin{tabular}{|c|c|c|c|c|c|rr|}
\hline 16 & a & 865,471 & b1 & 881,847 & b2 & $=$ & 1747,318 \\
\hline 865,471 & a & 528,357 & b1 & 532,085 & b2 & $=$ & 1060,442 \\
\hline
\end{tabular}

\begin{tabular}{|l|l|c|c|c|c|r|}
\hline 13847,536 & a & 749040,0518 & b1 & 763213,0049 & b2 & $=1512253,057$ \\
\hline 13847,536 & a & 8454 & b1 & 8513,36 & b2 & $=16967,072$ \\
\hline
\end{tabular}

\begin{tabular}{|l|l|l|l|l|}
\hline 740586 & b1 & 754700 & b2 & $=1495286$ \\
\hline
\end{tabular}

Persamaan 2

\begin{tabular}{|c|c|c|c|c|c|r|}
\hline 16 & a & 865,471 & b1 & 881,847 & b2 & $=1747,318$ \\
\hline 865,471 & a & 532,085 & b1 & 537,718 & b2 & $=1069,80$ \\
\hline
\end{tabular}

\begin{tabular}{|c|c|c|c|c|c|c|c|}
\hline 13847,536 & $\mathrm{a}$ & 749040,0518 & b1 & 763213,0049 & b2 & \multicolumn{2}{|c|}{$=1512253,057$} \\
\hline 13847,536 & $\mathrm{a}$ & 8513 & b1 & 8603,488 & b2 & $=$ & 17116,8 \\
\hline & & 740527 & b1 & 754610 & b2 & $=$ & 1495136 \\
\hline
\end{tabular}

Persamaan 3

\begin{tabular}{|l|l|l|l|r|}
\hline 740586 & b1 & 754700 & b2 & $=$ \\
\hline 740527 & b1 & 754610 & b2 & 1495286 \\
\hline 548423954635 & b1 & 558875463966 & b2 & $=1107299644450$ \\
\hline 548423954635 & b1 & 558853502572 & b2 & $=1107277492755$ \\
\hline
\end{tabular}

\begin{tabular}{|c|c|c|c|}
\hline 21961394 & b2 & $=$ & 22151694 \\
\hline & b2 & & 1,0087 \\
\hline
\end{tabular}


Persamaan $1+\mathrm{b} 2$

\begin{tabular}{|c|c|c|c|c|}
\hline 740586 & b1 & 754700 & b2 & 1495286 \\
\hline 740586 & b1 & 754700 & 1,0087 & 1495286 \\
\hline 740586 & b1 & 761265,5318 & 1495286 & \\
\hline 740586 & b1 & 2256551,532 & & \\
\hline & b1 & 3,0470 & & \\
\hline
\end{tabular}

Persamaan rumus $1+\mathrm{b} 1+$

b2

$16 \mathrm{a}+865,471 \mathrm{~b} 1+881,847 \mathrm{~b} 2=1747,318$

$16 \mathrm{a}+865,471(3,0470)+881,847(1,0087)=1747,318$

$16 \mathrm{a}+2637,09+889,519=1747,318$

$16 \mathrm{a}+3526,609=1747,318$

$16 \mathrm{a}=1747,318-3526,609$

$16 \mathrm{a}=-1779,291$

$\mathrm{a}=1779,291 / 16$

$a=-\mathbf{1 1 1 , 2 0 5}$

$\mathrm{Y}=-111,205+3,0470+1,0087$

$\mathrm{Y}=-111,205+3,0470(865471)+1,0087(881847)$

$\mathrm{Y}=3415404 * 1000 / 100$

$Y=34154,04$

Setelah didapat nilai a, x1, x2 selanjutanya kita hitung jumlah penduduk dan dan jumlah pengangguran sebagai berikut : 
Tabel.6 Hasil perhitungan

\begin{tabular}{|l|l|l|}
\hline Jumlah Penduduk 2017 & $:$ & 1.747 .318 \\
\hline Perkiraan Jumlah Penduduk Bertambah & $:$ & 34.154 \\
\hline Jumlah Penduduk 2018 & $:$ & 1.781 .472 \\
\hline Jumlah perkiraan pengangguran 3,5\% dari seluruh jumlah penduduk & $:$ & 62.352 \\
\hline
\end{tabular}

Dari tabel diatas dapat dilihat bahwa jumlah penduduk tahun 2017 sebanyak 1.747.318, perkiraan jumlah penduduk bertambah 34.154, dan pada tahun 2018 jumlah penduduk 1.781.472, maka dapat dilihat jumlah perkiraan pengangguran 3,5\% dari seluruh jumlah penduduk, berikut grafiknya :

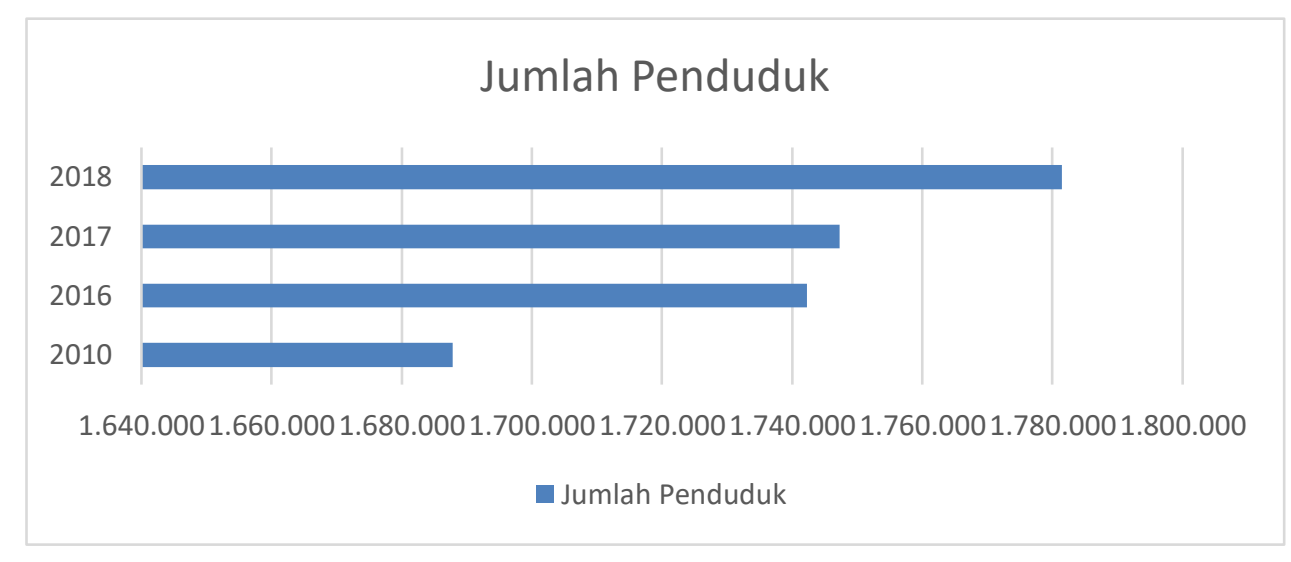

Gambar 2 Jumlah penduduk

Tabel 9 jumlah pengangguran pertahun

\begin{tabular}{|l|r|}
\hline \multicolumn{2}{|c|}{ Jumlah Pengangguran } \\
\hline 2017 & 21.478 \\
\hline 2018 & 62.352 \\
\hline
\end{tabular}

Berikut Grafiknya :

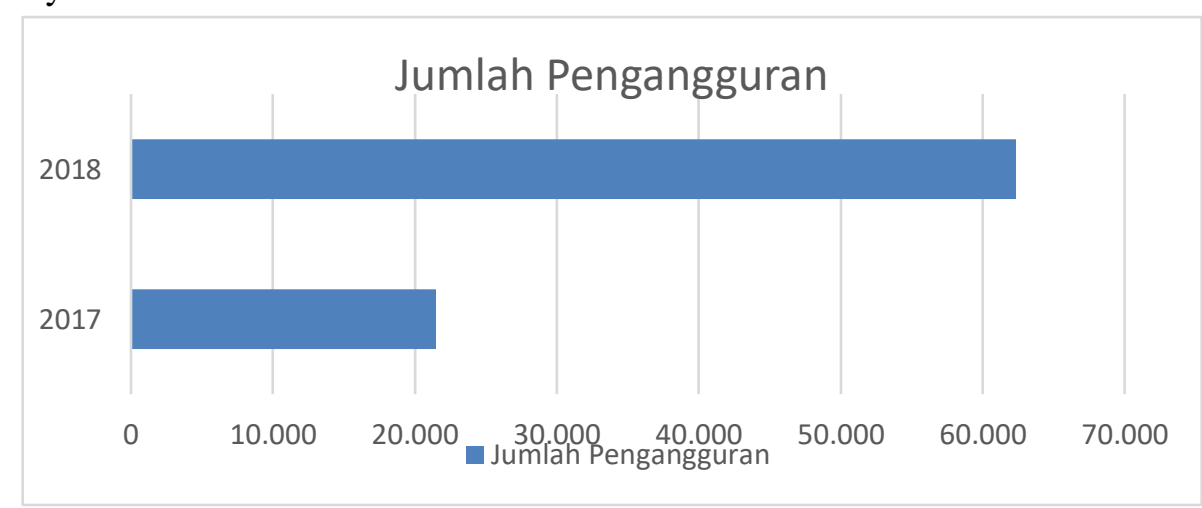

Gambar 3 Jumlah pengangguran

Grafik diatas merupakan grafik jumlah penduduk yang dihitung pertahun dan grafik jumlah pengangguran pada tahun 2017 dan 2018. 
Berdasarkan pengujian dan evaluasi yang telah dilakukan, Hasil estimasi menggunakan metode regresi linear berganda untuk jumlah pengangguran pada tahun 2018 mencapai 62.352 orang. Maka estimasi menggunakan metode regresi linear berganda dapat dijadikan referensi dalam melakukan perhitungan jumlah pengangguran di Taskmalaya.

\section{KESIMPULAN}

Berdasarkan pengujian dan evaluasi yang telah dilakukan, Hasil estimasi menggunakan metode regresi linear berganda untuk jumlah pengangguran pada tahun 2018 mencapai 62.352 orang. Maka estimasi menggunakan metode regresi linear berganda dapat dijadikan referensi dalam melakukan perhitungan jumlah pengangguran di Taskmalaya.

Hasil dari analisa yang diperoleh dari data mining dengan metode Regresi Linear Berganda mengenai prediksi laju pertumbuhan penduduk dapat membantu pihak Badan Pusat Statistik Kabupaten Tasikmalaya mengetahui atribut/kriteria apa saja yang mempengaruhi laju pertumbuhan penduduk. Dan juga ditemukan pola yang saling berkaitan erat antara atribut jumlah jenis kelamin dan umur terhadap estimasi pengangguran di Kabupaten Tasikmalaya.

\section{DAFTAR PUSTAKA}

[1] Badan Pusat Statistik Kabupaten Tasikmalaya, 2018. Jumlah Penduduk dan laju pertumbuhan Kabupaten Tasikmalaya.

[2] Mulyani, E.D.S., Septianingrum, I., Nurjanah, N., Rahmawati, R., Nurhasani, S. and RK, K.M., 2019. Prediksi Curah Hujan Di Kabupaten Majalengka Dengan Menggunakan Algoritma Regresi. E-JURNAL JUSITI: Jurnal Sistem Informasi dan Teknologi Informasi, 8(1), pp.67-77.

[3] Ali Fikri, 2009. Penerapan Data Mining Untuk Mengetahui Tingkat Kekuatan Beton Yang Dihasilkan Dengan Metode Estimasi Menggunakan Linear Regression.

[4] Purwadi, Puji Sari Ramadhan, Nurdiyanti Safitri,2018. Penerapan Data Mining Untuk Mengestimasi Laju Pertumbuhan Penduduk Menggunakan Metode Regresi Linier Berganda Pada BPS Deli Serdang.

[5] Rahmat Mahmuda, 2018. Peningkatan Angka pengangguran dikota Tasikmalaya.

[6] Sugiarto dan Dergibson, S. 2002. Metode Statistika Untuk Bisnis dan Ekonomi. Jakarta: PT. Gramedia Pustaka Utama. Hal 208-217.

[7] Mulyani, E.D.S., Mulady, F., Ramadhan, D., Ariyantono, A., Ramdani, D., Wahyundana, R. and Gilang, M., 2020. Estimasi Harga Jual Mobil Bekas Menggunakan Metode Regresi Linier Berganda. E-JURNAL JUSITI: Jurnal Sistem Informasi dan Teknologi Informasi, 9(1), pp.1-8.

[8] Ali Fikri, 2009. Penerapan Data Mining Untuk Mengetahui Tingkat Kekuatan Beton Yang Dihasilkan Dengan Metode Estimasi Menggunakan Linear Regression. 